\title{
A multiphase flow in the antroduodenum: some results of the mathematical modelling and computational simulation
}

\author{
Marat Kamaltdinov ${ }^{1, *}$, Peter Trusov ${ }^{2}$, and Nina Zaitseva ${ }^{1}$ \\ ${ }^{1}$ Federal Budget Scientific Institution "Federal Scientific Center for Medical and Preventive Health \\ Risk Management Technologies", Department of Mathematical Simulation of Systems and Processes, \\ 82 Monastyrskaya street, 614000, Perm, Russia \\ ${ }^{2}$ Perm National Research Polytechnic University, Department of Mathematical Simulation of \\ Systems and Processes, 29 Komsomolsky Prospect, 614000, Perm, Russia
}

\begin{abstract}
This work is devoted to a problem of creation of a multiphase flow model in an antroduodenum that includes the lower part of the stomach and the upper part of the small intestine (duodenum). The mathematical model is developed for the next purposes: description of the process of digestion in normal physiological state and with functional disorders, prediction of the flow characteristics in distinct conditions. The antroduodenum is considered as a complex form canal with moving boundaries. The mathematical statement of the problem includes mass and momentum conservation equations for phases and components as well as initial and boundary conditions with peristaltic movement. To describe secretion and absorption processes we use mass sources/sinks in a layer adjacent to the tract wall. Using computational simulation we got the digestion processes characteristics in dynamic: $\mathrm{pH}$ of the medium, components and phases velocities and fractions. In some scenarios with secretory and motor disorders we identified zones of abnormal acidity. The results of the simulation showed that motor functionality of the antrum and pyloric sphincter affect the stomach evacuation. Additionally, the chemical absorption rate is analyzed in scenarios with distinct food parameters (size, viscosity, density).
\end{abstract}

\section{Introduction}

Diseases of the gastrointestinal tract (GIT) hold high position in the structure of digestive system pathologies. Note there was a percentage increase of global incidence of gastritis and duodenitis (18.3\%) and peptic ulcer diseases (4.8\%) between 2005 and 2015 [1]. Although the prevalence of atrophy in the stomach and the incidence of peptic ulcer disease decrease in some countries [2,3], we observe reports that the prevalence of atrophic corpus gastritis and duodenitis is still high. It is about from 5 to $12 \%$ for distinct countries and age groups [4-6]. Additionally, it is well known that the chemicals found in drinking water and food can increase health risk $[7,8]$.

\footnotetext{
* Corresponding author: kmr@fcrisk.ru
} 
For a deeper understanding the pathological processes we are working on a multilevel mathematical model which describes accumulation of damages in a human body, associated with environmental exposure [9]. The upper level of the model deals with averaged interaction of body systems. For more detailed description we considers "meso-level" models of the cardiovascular, respiratory [10], digestive, neuro-endocrine [11], and other systems.

This work is devoted to the problems of development of the antroduodenum model, that details damages to antroduodenum caused by acid and other chemicals from the tract cavity. CFD (Computation Fluid Dynamics) models meet these purposes, allowing to assess and predict flow characteristics at any point of simulation domain. Nowadays models of fluid flow in the esophagus [12, 13], stomach [14, 15] and bowel [16-18] are developing rapidly. Available models of the stomach or duodenum mainly account for the peristaltic waves in the antrum $[19,20]$ and gut $[21]$. Researchers mostly consider single-phase flow without biochemical reactions, secretion of the digestive glands and functional disorders of the tract. Only separate interesting aspects are considered in some cases, for example, diffusion of mixture component (pepsin) in the stomach lumen [22], transfer of the mixture through the pyloric sphincter [23], pouch emptying of a patient after gastric surgery [24]. Xue et. al showed that particle phase had a sufficient impact on the flow characteristics [25], but the mass exchange between phases due to the food dissolution were not considered. Also, available literature does not address CFD models describing acidity in the tract. Thus, it is necessary to continue development of the flow models in the gastrointestinal tract. Particularly, we should pay attention to individual patient parameters and diseases.

For a more detailed description we presented a multiphase flow model in the 3D antroduodenum allowing for the mass sources/sinks due to particle dissolution, reactions between components, mixture components secretion and absorption, peristaltic movement, functional disorders of the tract [26]. The antroduodenum is a section of the gastrointestinal tract that includes the lower part of the stomach (antrum), the upper part of the small intestine (duodenum) and the pyloric outlet that divides antrum and duodenum. The mathematical model is developed for the next purposes: description of the process of digestion in a normal physiological state and with functional disorders, prediction of the flow characteristics in the distinct conditions. In this paper we consider some variants of the model application and results of computational simulation.

\section{Conceptual statement}

We consider a digestion stage when stomach evacuation begins and the temperature of the multiphase media in the stomach is equal to the body temperature. At first approximation all processes are considered to be isothermal. The first phase is a multicomponent liquid with components dissolved at the molecular level: water, hydrochloric acid, sodium bicarbonate, the reaction product with hydrochloric acid and sodium bicarbonate (carbon dioxide and sodium chloride), dissolved proteins, fats, carbohydrates, chemicals, polypeptides, and pepsin. Food particles of different sizes are considered as separate liquid phases and dissolved under the action of hydrochloride acid. Besides, the model takes into consideration an acid neutralization reaction with sodium hydrogen carbonate and enzymatic reaction of pepsin and protein.

The antroduodenum is considered as a complex form canal with moving boundaries. Antroduodenum motility is assumed to be periodical in the model; it allows for peristaltic waves in the antrum and duodenum as well as for pyloric sphincter contraction. Wave processes parameters are thought to be independent of tract contents properties. To describe the secretion and absorption processes we use mass sources in a layer adjacent to the tract 
wall. When describing sodium bicarbonate secretion, we allowed for functionality of control signalling through neuro-endocrine mechanisms. Receptors are assumed to determine acidity level in the stomach body and give signals to change intensity of sodium bicarbonate mass source in the antroduodenum.

We consider only absorption of chemicals in the antroduodenum because nutrients absorption is not particular for this area of the tract. The amount of chemicals absorbed into blood is proportional to the difference between concentration at the border of the tract cavity and the blood concentrations. Absorption rate does not depend on the flow characteristics and it is defined by physicochemical properties of the toxicant.

We divided all modelling area into four sections: acid and alkaline secretion zones in the stomach, pyloric outlet with duodenum and area of the inflow of the pancreatic juice. Each $l$-th section of the tract wall has its own damage $D_{(l)(m)} \in[0 ; 1]$ in terms of accomplishing $m$-th function. Functionality of the tract wall section is related to the damage by the following formula: $F_{(l)(m)}=1-D_{(l)(m)}$, functionality that is different from 1, is shown by a quantitative reduction of the secretory $F_{(l)(1)}$, absorption $F_{(l)(2)}$ and motor $F_{(l)(3)}$ tract functions. We assume that when disorders in secretory function of the stomach body occur it results in a decrease of the intensity of hydrochloric acid mass source. From the medical point of view, hyposecretion can be a sign of atrophic gastritis with various severity degree [27]. We don't deal with acid hypersecretion as it can rather be caused by regulation disorders while decreased secretion can result from damage to secretory cells. Similarly, the model considers only decrease in the intensity of sodium bicarbonate mass source of the antrum, duodenum, pancreas. Disorders in motor function become apparent via decrease in peristaltic waves amplitude in the antrum and duodenum, or in weaker contraction of the pyloric sphincter which can be caused by weakness of muscles in the circular layers of the tract walls. Other motility disorders, for example, changes in contractions periodicity are not considered. Disorders in absorption function reduce income rate to the blood because chemicals can change wall properties of the tract. It is one of the tolerance mechanisms.

\section{Mathematical statement}

The mathematical statement of the problem includes mass and momentum conservation equations for the phases and components as well as initial and boundary conditions with peristaltic movement.

Generally advection-diffusion equations for the first phase components can be given as:

$$
\begin{gathered}
\frac{\partial}{\partial t}\left(\rho_{(1)} \alpha_{(1)} Y_{(i)}\right)+\nabla \cdot\left(\rho_{(1)} \alpha_{(1)} \mathbf{v}_{(1)} Y_{(i)}\right)=-\nabla \cdot \mathbf{J}_{(i)}+R_{(i)}+S_{(i)}+\sum_{j} m_{(j)(i)}^{\prime}, \\
\mathbf{r} \in \bar{\Omega}, t \in[0 ; T), i=\overline{0, I}, j=\overline{2, J}
\end{gathered}
$$

where $i$ is a component index of the first phase; $j$ is a phase index, index $j=1$ corresponds to the first phase which is a multicomponent liquid, index $j>1$ corresponds to phases of food particles with different sizes, which in first approximation are described with a model of Newtonian liquid with different viscosity; $\rho_{(j)}$ is a density of the $j$-phase, $\mathrm{kg} / \mathrm{m}^{3} ; \alpha_{(j)}$ is a volume fraction of the $j$-phase; $Y_{(i)}$ is a mass fraction of the $i$-component of the first phase; $\nabla$ is a nabla operator; $\nabla \cdot$ is a divergence operator; $\mathbf{v}_{(j)}$ is a velocity of the $j$-phase, $\mathrm{m} / \mathrm{s} ; \mathbf{J}_{(i)}$ is an intensity of mass flow of the first phase $i$-component due to 
diffusion processes, $\mathrm{kg} /\left(\mathrm{m}^{2} \cdot \mathrm{s}\right) ; R_{(i)}$ is an intensity of mass sources of the first phase $i$ component due to reactions between components, $\mathrm{kg} /\left(\mathrm{m}^{3} \cdot \mathrm{s}\right) ; S_{(i)}$ is a mass sources intensity of the $i$-component due to secretion/absorption, $\mathrm{kg} /\left(\mathrm{m}^{3} \cdot \mathrm{s}\right) ; m_{(j)(i)}^{\prime}$ is an augend in mass balance equation, determining the transition intensity from $j$-phase into the first phase $i$ component, $\mathrm{kg} /\left(\mathrm{m}^{3} \cdot \mathrm{s}\right) ; t$ is an independent variable (time), $\mathrm{s} ; \Omega$ is an interior of the whole area; $\partial \Omega$ is the area boundary; $\bar{\Omega}=\Omega \cup \partial \Omega$ is the area closure (area interior and its boundary); $\partial \Omega_{l)}$ is $l$ - boundary of area, $l=\overline{1, L}$; we introduce secretion as mass sources in layer adjacent to the tract wall, so we define $\Omega_{l)}$ as internal layer adjacent to the $l$ boundary, $l=\overline{1, \mathrm{~L}}$.

The mass conservation equations for the liquid phases of the food particles in general terms can be expressed as:

$$
\begin{gathered}
\frac{\partial}{\partial t}\left(\rho_{(j)} \alpha_{(j)}\right)+\nabla \cdot\left(\rho_{(j)} \alpha_{(j)} \mathbf{v}_{(j)}\right)=-\sum_{i} m_{(j)(i)}^{\prime}+m^{\prime \prime}{ }_{(j-1)(j)}-m^{\prime \prime}{ }_{(j)(j+1)}, \\
\quad \mathbf{r} \in \bar{\Omega}, t \in[0 ; T), i=\overline{0, I}, j=\overline{2, J}, m^{\prime \prime}{ }_{(1)(2)}=m^{\prime \prime}{ }_{(J)(J+1)}=0,
\end{gathered}
$$

where $m^{\prime \prime}{ }_{(j-1)(j)}$ is an augend in mass balance equation, determining the transition intensity from $(j-1)$-phase into $j$-phase, $\mathrm{kg} /\left(\mathrm{m}^{3} \cdot \mathrm{s}\right)$.

The system of mass conservation equations is complemented by the following 2 equations:

$$
\sum_{i} Y_{(i)}=1, \sum_{j} \alpha_{(j)}=1, i=\overline{0, I}, j=\overline{1, J}
$$

The momentum-conservation equations can be written as:

$$
\begin{gathered}
\frac{\partial}{\partial t}\left(\alpha_{(1)} \rho_{(1)} \mathbf{v}_{(1)}\right)+\nabla \cdot\left(\alpha_{(1)} \rho_{(1)} \mathbf{v}_{(1)} \mathbf{v}_{(1)}\right)=-\alpha_{(1)} \nabla p+\nabla \cdot \boldsymbol{\tau}_{(1)}+ \\
+\alpha_{(1)} \rho_{(1)} \mathbf{g}+\sum_{j} K_{(j)(1)}\left(\mathbf{v}_{(j)}-\mathbf{v}_{(1)}\right)+\sum_{j}\left(\sum_{i=3,4,5,6,9} m_{(j)(i)}^{\prime} \mathbf{v}_{(j)}\right), \\
\frac{\partial}{\partial t}\left(\alpha_{(j)} \rho_{(j)} \mathbf{v}_{(j)}\right)+\nabla \cdot\left(\alpha_{(j)} \rho_{(j)} \mathbf{v}_{(j)} \mathbf{v}_{(j)}\right)=-\alpha_{(j)} \nabla p+\nabla \cdot \boldsymbol{\tau}_{(j)}+\alpha_{(j)} \rho_{(j)} \mathbf{g}+ \\
+\sum_{q} K_{(q)(j)}\left(\mathbf{v}_{(q)}-\mathbf{v}_{(j)}\right)-\left(\sum_{i=3,4,5,6,9} m_{(j)(i)}^{\prime}\right) \mathbf{v}_{(j)}+m^{\prime \prime(j-1)(j)} \mathbf{v}_{(j-1)}-m^{\prime \prime(j)(j+1)} \mathbf{v}_{(j)}, \\
\mathbf{r} \in \Omega, t \in[0 ; T), j=\overline{2, J}, q=\overline{1, J}, m^{\prime \prime(1)(2)}=m_{(J)(J+1)}=0, \\
\boldsymbol{\tau}_{(j)}=\alpha_{(j)} \eta_{(j)}\left[\nabla \mathbf{v}_{(j)}+\left(\nabla \mathbf{v}_{(j)}\right)^{T}\right], j=\overline{1, J}, \mathbf{r} \in \bar{\Omega},
\end{gathered}
$$

where $p$ is a pressure, $\mathrm{Pa} ; \boldsymbol{\tau}_{(j)}$ is a deviatoric part of Cauchy stress tensor of the $j$-phase, $\mathrm{Pa} ; \mathbf{g}$ is a vector characterizing mass force impact, $\mathrm{m} / \mathrm{s}^{2} ; K_{(j)(q)}$ is a coefficient of interphase interaction $j$ and $q$-phase, $\mathrm{kg} /\left(\mathrm{m}^{3} \cdot \mathrm{s}\right), \eta_{(j)}$ is a shear viscosity of the $j$-phase, Pa.s.

We pass by detailed description of mass sources terms in order not to overload the paper. Kinematic boundary conditions on the antroduodenum walls and conditions of 
components zero flow through the boundary are set allowing for peristaltic motion (no slip condition):

$$
\begin{aligned}
& \mathbf{v}_{(j)}(t, \mathbf{r})=\mathrm{d} \mathbf{r}(t) / \mathrm{d} t, \quad \frac{\partial Y_{(i)}}{\partial n}=0, \\
& i=\overline{0, I}, \quad j=\overline{1, J}, \quad t \in[0 ; T), \quad \mathbf{r}(t) \in \partial \Omega_{(l)}, \quad l=\overline{2,5},
\end{aligned}
$$

where $\mathbf{r}(t) \in \partial \Omega_{l l}$ is a radius vector of material point on the antroduodenum wall in the gastrointestinal tract. The peristaltic wave amplitude is proportional to the functionality $F_{(l)(3)}$. Values for mass fractions of the first phase components, pressure and conditions for tangent components of stress vector being equal to zero are set on the rest of the examined area boundaries (inlet/outlet sections):

$$
\begin{gathered}
Y_{(i)}=Y_{(i)}^{\partial \Omega}, \mathbf{n} \cdot \boldsymbol{\sigma}_{(j)} \cdot \mathbf{n}=p, \mathbf{t}_{(j)}-\left(\mathbf{n} \cdot \boldsymbol{\sigma}_{(j)} \cdot \mathbf{n}\right) \mathbf{n}=\mathbf{0}, \mathbf{t}_{(j)}=\mathbf{n} \cdot \boldsymbol{\sigma}_{(j)}, \\
t \in[0 ; T), \mathbf{r} \in \partial \Omega_{(l)}, l=1,6 .
\end{gathered}
$$

Equation system is completed with initial conditions:

$$
\alpha_{(j)}(t, \mathbf{r})=\alpha_{(j)}^{0}, Y_{(i)}(t, \mathbf{r})=Y_{(i)}^{0}, \mathbf{v}_{(j)}(t, \mathbf{r})=\mathbf{v}_{(j)}^{0}, \mathbf{r} \in \bar{\Omega}, t=0 .
$$

Major difficulties related to parameters identification are caused by determining spatially distributed flow characteristics of the gastric content at various digestion stages. At given stage, most of the parameters are determined on the basis of literature data [2831]. The results discussed in given paper are obtained on the example of an antroduodenal GIT section which is average statistical as per its geometric properties (size and shape). As a result of an ultrasonic study, stomach images were obtained and analyzed. The reconstruction algorithm of three-dimensional area is based on approximation of a real geometrical shape by a finite number of ellipses. Dynamic reconstruction of the computational grid during peristaltic activity is carried out with Fluent solver using the script in $\mathrm{C}$ programming language. Motility baseline parameters in the antrum (provided there are no functional disorders) are set as follows: periodicity is $18 \mathrm{~s}$, wave width is 0.02 $\mathrm{m}$, amplitude is $0.011 \mathrm{~m}$. The wave starts in the middle part of stomach body and spreads towards the pyloric outlet at the velocity equal to $0.0022 \mathrm{~m} / \mathrm{s}$ for $38 \mathrm{~s}$. Waves parameters in the duodenum are as follows: periodicity is $9 \mathrm{~s}$, wave width is $0.04 \mathrm{~m}$, amplitude is 0.0035 $\mathrm{m}$; the wave starts near the pyloric outlet and spreads at the velocity equal to $0.005 \mathrm{~m} / \mathrm{s}$ for $36 \mathrm{~s}$. The pyloric opening opens and closes for $2 \mathrm{~s}$ each $18 \mathrm{~s}$. So, under the set parameters, motility of the antrum, pyloric opening and duodenum is synchronized. The calculated area geometry occasionally changes.

\section{Results and discussion}

Using computational simulation we got the digestion processes characteristics in dynamic: $\mathrm{pH}$ of the medium, components and phases velocities and fractions. We analyzed zones of high acidity, processes of stomach evacuation and chemical absorption in some scenarios. 


\subsection{Acidity in the tract}

We identified zones of abnormal acidity in some scenarios with initially increased acidity (for example, due to acidic drink intake), secretory [32] and motor disorders. On the whole we can note that if there are no functional disorders, sodium hydrogen carbonate neutralizes excessive acidity in antroduodenum more efficiently when a drink in a set volume with $\mathrm{pH}$ $>3.5$ is consumed. An area with small acidity (from 5 to $7 \mathrm{pH}$ ) evolves in near-wall layers of the antrum and duodenum cavity to protect from negative influence. Drinks with $\mathrm{pH}=2.3$ have much greater damaging potential and are much more harmful for the mucous coat of the GIT walls. In this case abnormally low $\mathrm{pH}$ levels are observed in the duodenal cap area $(\mathrm{pH}=3)$. But if any disorders in alkaline secretion appear the situation becomes substantially worse as an area of potential damage to the tract walls grows. In this case high acidity of a mixture $(\mathrm{pH}=2.5)$ is detected near both the concave and convex walls of the duodenum. If there are disorders in the antrum motor function, acidic contents of the stomach transfer into the bowels slower and the duodenum neutralizes excessive acidity.

\subsection{Stomach evacuation}

We considered five phases of food particles with different sizes. Initial placement of particles phases is in the stomach only. Food particle distribution in the process of crashing in oral cavity is obtained on the basis of Rosin-Rammler equation modification considering functional disorders of the dentofacial system. Parameters of the distribution function were set for carrots (20 chewing cycles, functionality of the chewing equals 1 ) based on available literature [33]. In case with functional disorders particles sizes are much greater (Table 1). At the beginning of the numerical simulation, the first phase contains only a water component $\left(\rho_{(1)}=1000 \mathrm{~kg} / \mathrm{m}^{3}, \eta_{(j)}=10^{-3} \mathrm{~Pa} \cdot \mathrm{s}\right)$. The density of food particles equals to 1005 $\mathrm{kg} / \mathrm{m}^{3}$, viscosity is $2 \cdot 10^{-3} \mathrm{~Pa} \cdot \mathrm{s}$.

Table 1. Sizes of the particles phases.

\begin{tabular}{|c|c|c|c|}
\hline No. & $\begin{array}{c}\text { Medium } \\
\text { size, } \mathbf{~ m m}\end{array}$ & $\begin{array}{c}\text { Fraction with dentition } \\
\text { functionality }=\mathbf{1}, \alpha_{(j)}^{0}\end{array}$ & $\begin{array}{c}\text { Fraction with chewing } \\
\text { functionality }=\mathbf{0 . 5}, \alpha_{(j)}^{0}\end{array}$ \\
\hline$j=1$ & - & 0.1 & 0.1 \\
\hline$j=2$ & 3.6 & 0.066 & 0.510 \\
\hline$j=3$ & 2.8 & 0.165 & 0.160 \\
\hline$j=4$ & 1.7 & 0.516 & 0.195 \\
\hline$j=5$ & 0.7 & 0.132 & 0.031 \\
\hline$j=6$ & 0.2 & 0.021 & 0.005 \\
\hline
\end{tabular}

The results of the simulation showed that motor functionality of the antrum and pyloric sphincter affect the stomach evacuation (Table 2). Functional disorders in the antrum are considered at two levels ( 1 and 0.75 ) and maximal wave amplitudes are $11 \mathrm{~mm}$ and 8.25 $\mathrm{mm}$ respectively. Functional disorders in the pyloric outlet are considered at four levels (1, $0.9,0.5$ and 0 ) which correspond to distinct levels of incomplete closure. In $324 \mathrm{~s}$ some mass of the dissolved food components and food particles are observed in the duodenum due to the stomach evacuation process. The particles sized $\geq 1.7 \mathrm{~mm}$ do not evacuate into the bowel, but settle into the lower part of the stomach. This particles need to be dissolved for evacuation to the gut. The obtained results correspond to the available experimental 
data, some studies have shown that the food particles sized $<2 \mathrm{~mm}$ are evacuated during fed motility [34].

Table 2. Results in scenarios with disorders of GIT motor function, $t=324 \mathrm{~s}$.

\begin{tabular}{|c|c|c|c|c|c|}
\hline No. & $\begin{array}{c}\text { Functional } \\
\text { disorders } \\
\text { in the } \\
\text { antrum } \\
\text { motility }\end{array}$ & $\begin{array}{c}\text { Functional } \\
\text { disorders in } \\
\text { the pyloric } \\
\text { outlet } \\
\text { motility }\end{array}$ & $\begin{array}{c}\text { Mass of the } \\
\text { dissolved food } \\
\text { components in } \\
\text { the duodenum, } \\
\boldsymbol{g}\end{array}$ & $\begin{array}{c}\text { Mass of the } \\
\text { particles with } \\
\text { average size 0.7 } \\
\text { mm in the } \\
\text { duodenum, } \boldsymbol{g}\end{array}$ & $\begin{array}{c}\text { Mass of the } \\
\text { particles with } \\
\text { average size 0.2 } \\
\text { mm in the } \\
\text { duodenum, } \boldsymbol{g}\end{array}$ \\
\hline 1 & 1 & 1 & 0.064 & 0.762 & 0.524 \\
\hline 2 & 1 & 0.9 & 0.064 & 0.792 & 0.538 \\
\hline 3 & 1 & 0.5 & 0.073 & 0.414 & 0.419 \\
\hline 4 & 1 & 0 & 0.072 & 0.393 & 0.378 \\
\hline 5 & 0.75 & 1 & 0.046 & 0.077 & 0.205 \\
\hline 6 & 0.75 & 0.9 & 0.045 & 0.081 & 0.209 \\
\hline 7 & 0.75 & 0.5 & 0.046 & 0.081 & 0.215 \\
\hline 8 & 0.75 & 0 & 0.046 & 0.095 & 0.221 \\
\hline
\end{tabular}

It is important to note that food mass in the duodenum are much lower in scenarios with antrum disorders. First of all, mass of the particles with size $0.7 \mathrm{~mm}$ is approximately ten times lower ( 0.762 and $0.077 \mathrm{~g}$ in scenarios 1 and 5 respectevily). There is a weak relation of the pyloric outlet motility to the stomach evacuation in scenarios 5-8. Thus, movement of the large particles is more dependent on the antrum motor functionality. When the gastric outlet is opening, the particles sized $0.7 \mathrm{~mm}$ transit into the bowel at $0.026 \mathrm{~m} / \mathrm{s}$ and 0.016 $\mathrm{m} / \mathrm{s}$ in scenarios 1 and 5 respectevily (Fig. 1 ).
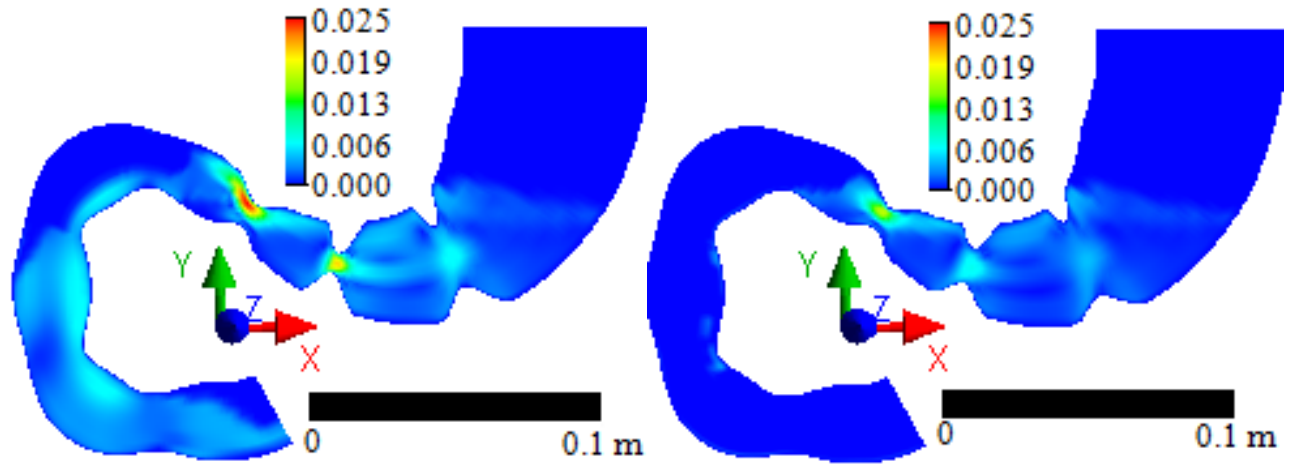

Fig. 1. Absolute values of velocities in the antroduodenum (scenario 1 is on the left, scenario 2 is on the right)

Results showed that mass of the dissolved food components in scenarios 3 and 4 is a little more than in scenarios 1 and 2. Components easily pass through incomplete closure of the pyloric outlet. But mass of the particles is in 1.5-2 times lower in scenarios 3 and 4 . Probably, co-operative work of the antrum and pyloruc outlet muscles is needed for succesful particles transition to the duodenum. 


\subsection{Chemical absorption}

The chemical absorption rate is analyzed in scenarios with functional disorders and distinct food parameters (size, viscosity, density). For example, we used lead parameters, the diffusion coefficient is taken as $5.12 \cdot 10^{-10} \mathrm{~m}^{2} / \mathrm{s}$, and the permeability coefficient is taken as $3.34 \cdot 10^{-3} \mathrm{~s}^{-1}$. Another model parameters are presented in Table 3.

Table 3. Model parameters for analysis of the chemical absorption rate.

\begin{tabular}{|c|c|c|c|c|c|}
\hline No. & $\begin{array}{c}\text { Functional } \\
\text { disorders in } \\
\text { the alkaline } \\
\text { secretion }\end{array}$ & $\begin{array}{c}\text { Functional } \\
\text { disorders in } \\
\text { the antrum } \\
\text { motility }\end{array}$ & $\begin{array}{c}\text { Density of } \\
\text { particles } \\
\text { phases, } \\
\mathbf{k g} / \mathbf{m} 3\end{array}$ & $\begin{array}{c}\text { Viscosity of } \\
\text { particles } \\
\text { phases, Pa·s }\end{array}$ & $\begin{array}{c}\text { Functional } \\
\text { disorders in the } \\
\text { chewing } \\
\text { function }\end{array}$ \\
\hline 1 & 1 & 1 & 1020 & $2 \cdot 10^{-3}$ & 1 \\
\hline 2 & 1 & 1 & 1005 & $2 \cdot 10^{-3}$ & 1 \\
\hline 3 & 1 & 1 & 1005 & $10^{-1}$ & 1 \\
\hline 4 & 0.5 & 1 & 1005 & $2 \cdot 10^{-3}$ & 1 \\
\hline 5 & 1 & 0.75 & 1005 & $2 \cdot 10^{-3}$ & 1 \\
\hline 6 & 1 & 1 & 1005 & $2 \cdot 10^{-3}$ & 0.5 \\
\hline
\end{tabular}

Modelling results showed that maximal absorption rate in the antroduodenum are observed in scenario 4 (up to $4.38 \cdot 10^{-14} \mathrm{~kg} / \mathrm{s}$ for a moment time equals $324 \mathrm{~s}$ ). In this case high acidity in the tract enhance particles dissolution and chemical concentration increases faster. We observed that chemical absorption rate reached $3.94 \cdot 10^{-14} \mathrm{~kg} / \mathrm{s}$ in scenario 2 without functional disorders. Functional disorders in the antrum motility, high particles viscosity and high density lead to weaker food mixing and dissolution, therefore the absorption rate reduces. We observed that absorption rate values are $3.16 \cdot 10^{-14}, 2.83 \cdot 10^{-14}$ and $2.63 \cdot 10^{-14} \mathrm{~kg} / \mathrm{s}$ in scenarios 5,3 and 1 respectively. In scenario 6 we saw minimal values $\left(1.29 \cdot 10^{-14} \mathrm{~kg} / \mathrm{s}\right)$ for absorption process. Mass fraction of the largest particles in the stomach are very high in this case (more than $50 \%$ ). These particles need more time to dissolute, therefore lead concentration is relatively low.

\section{Conclusion}

Thus, given approaches allows to describe the process of the multiphase flow in the antroduodenum both as normal and as under pathological disorders. In this paper we proposed some variants of model application. On the one hand, mathematical modelling can improve our understanding of the digestive processes. On the other hand, usage of individual patient parameters may lead to medical and prophylactic recommendations based on modelling results as in the case of cardiovascular system. This is a future model perspective.

Further identification of the model parameters is the next important step. It is necessary to carry out experimental research on determination of the rheological characteristics of the contents of the digestive tract, also viscosity and density of the media are not constant and must change in the process of the digestion.

The reported study was funded by RFBR according to the research project № 16-01-00126 A 


\section{References}

1. GBD 2015 Disease and Injury Incidence and Prevalence Collaborators, Lancet 388(10053), 1545-1602 (2016)

2. T. Kamada, K. Haruma, M. Ito, K. Inoue, N. Manabe, H. Matsumoto, H. Kusunoki, J. Hata, M. Yoshihara, K. Sumii, T. Akiyama, S. Tanaka, A. Shiotani, D.Y. Graham, Helicobacter 20(3), 192-198 (2015)

3. H. Malmi, H. Kautiainen, L.J. Virta, N. Färkkilä, J. Koskenpato, M.A. Färkkilä, Aliment Pharmacol Ther 39(5), 496-506 (2014)

4. L.D. Roman, R. Lukyanchuk, O.A. Sablin, E.I. Araslanova, C. Eklund, P. Hendolin, L. Paloheimo, K. Syrjänen, Anticancer Research 36(8), 4129-4138 (2016)

5. A. Alper, S. Hardee, D. Rojas-velasquez, S. Escalera, R.A. Morotti, D.S. Pashankar, J Pediatr Gastroenterol Nutr 62(2), 314-316 (2016)

6. H. Song, M. Held, S. Sandin, H. Rautelin, M. Eliasson, S. Söderberg, G. Hallmans, L. Engstrand, O. Nyrén, W. Ye, Clin Gastroenterol Hepatol 13(9), 1592-1600 (2015)

7. R. Kroes, D. Muller, J. Lambe, M. Lowik, J. van Klaveren, J. Kleiner, R. Massey, S. Mayer, I. Urieta, P. Verger, A. Visconti, Food Chemistry and Toxicology 40, 327-385 (2002)

8. A. Singh, R.K. Sharma, A. Agrawal, F.M. Marshall, Food and Chemical Toxicology 48(2), 611-619 (2010)

9. P.V. Trusov, N.V. Zaitseva, D.A. Kiryanov, M.R. Kamaltdinov, M.Yu. Tsinker, V.M. Chigvintsev, D.V. Lanin, Mathematical Biology and Bioinformatics 7(2), 589-610 (2012)

10. P.V. Trusov, N.V. Zaitseva, M.Yu. Tsinker, Mathematical Biology and Bioinformatics 11(1), 64-80 (2016)

11. N.V. Zaitseva, D.A. Kiryanov, D.V. Lanin, V.M. Chigvintsev, Computational and Mathematical Methods in Medicine 2014 (2014)

12. H. Gregersen, D. Liao, J.G. Brasseur, Ann N Y Acad Sci. 1380(1), 6-18 (2016)

13. W. Kou, A.P. Bhalla, B.E. Griffith, J.E. Pandolfino, P.J. Kahrilas, N.A. Patankar, Journal of Computational Physics 298, 446-465 (2015)

14. M.J. Ferrua, R.P. Singh, Current Opinion in Food Science 4, 116-123 (2015)

15. S. Hao, B. Wang, Y. Wang, European Journal of Pharmaceutical Sciences 70, 72-81 (2015)

16. L.A. Fullard, W.J. Lammers, M.J. Ferrua, Journal of Food Engineering 160, 1-10 (2015)

17. Y.F. Lim, C. de Loubens, R.J. Love, R.G. Lentle, P.W.M. Janssen, Food and Function 6, 1787-1795 (2015).

18. M.D. Sinnott, P.W. Cleary, S.M. Harrison, Applied Mathematical Modelling 44, 143159 (2017)

19. M.J. Ferrua, Z. Xue, R.P. Singh Journal of Biomechanics 47(15), 3664-3673 (2014)

20. Y. Imai, I. Kobayashi, S. Ishida, T. Ishikawa, M. Buist, T. Yamaguchi, American Journal of Physiology - Gastrointestinal and Liver Physiology 304(5), G536-G542 (2013)

21. S. De Loubens, R.G. Lentle, R.J. Love, C. Hulls, P.W.M. Janssen, Journal of the Royal Society Interface 10 (2013) 
22. H. Kozu, I. Kobayashi, M. Nakajima, K. Uemura, S. Sato, S. Ichikawa, Food Biophysics 5(4), 330-336 (2010)

23. S. Dillard, S. Krishnan, H. S. Udaykumar, World Journal of Gastroenterology 13(9), 1365-1371 (2007)

24. F. Gao, D. Liao, J. Zhao, A.M. Drewes, H. Gregersen, Obesity Surgery 18, 243-250 (2008)

25. Z. Xue, M. J. Ferrua, R.P. Singh, Alimentos Hoy 21(27), 3-13 (2012)

26. P.V. Trusov, N.V. Zaitseva, M.R. Kamaltdinov, Computational and Mathematical Methods in Medicine 2016 (2016)

27. P.H. Katelaris, F. Seow, B.P. Lin, J. Napoli, M.C. Ngu, D.B. Jones, Gut 34, 1032-1037 (1993)

28. A.J. Cornish-Bowden, J.R. Knowles, Biochemical Journal 113(2), 369-375 (1969)

29. N. Karmakar, G. Jayaraman, IMA Journal of Mathematics Applied in Medicine \& Biology 5(1), 33-43 (1988)

30. F. Kong, R.P. Singh, Food Biophysics 6, 84-93 (2011)

31. R.B. Voegborlo, A.M. El-Methnani, M.Z Abedin, Food Chemistry 67(4), 341-345 (1999)

32. M.R. Kamaltdinov, N.V. Zaitseva, P.Z. Shur, Health Risk Analysis, 1, 38-46 (2017)

33. M. A. Peyron, A. Mishellany, A. Woda, Journal of Dental Research, 83(7), 578-582 (2004)

34. F. Kong, R.P. Singh, Journal of Food Science, 73(5), R67-R80 (2008) 